\title{
Blockchain: an EOM approach to reconciliation in banking
}

\author{
Vedapradha $\mathrm{R}$ \\ Independent Researcher/Scholar, Bangalore, India, and \\ Hariharan Ravi \\ School of Commerce and Economics, Presidency University, Bangalore, India
}

\begin{abstract}
Purpose - The study aim is to evaluate the contribution of Blockchain technology (Cryptobanking) using expected operating model (EOM) to address the pain points in reconciliation at middle and back-office operational levels in assessing the significance of this technology on return on investment.

Design/methodology/approach - A structured questionnaire was designed to collect primary data using a stratified sampling method from 120 respondents working in leading Investment banks operating in the geographical locality of urban Bangalore. Demographic variables, accounting variables, data reporting variables, approach variables, variables of EOM were considered to validate the hypothesis with the help of statistical tools, namely ANOVA, and Multiple Stepwise Regression Analysis.

Findings - The results obtained confirm that there is significant difference in reconciliation with implementation of an innovative business process. Financial analysis is the highest predictor of ROI when integrated with technology as the adapted Blockchain innovation in reconciliation is the most influencing factor in enhancing, improving ROI playing a pivotal role in the Investment banks.

Originality/value - Blockchain technology (Cryptobanking) facilitates in transforming the reconciliation process of these banks with improved operational efficiency. Blockchain and settlement platforms offer interorganization solutions facilitating in the reconciliation of various transactions in real-time through a trustbased network in the form of digital settlements with better consortiums.
\end{abstract}

Keywords Application programming interface (API), Blockchain, Operational model, Reconciliation, Cryptobanking

Paper type Research paper

\section{Introduction}

Investment banks play a significant role in the economic development of a nation. They often deal with voluminous data at various levels of operations across the globe as an integral part of their banking business. Many industries embrace the blockchain technology due to its promising and crucial role in restructuring their business process primarily targeted toward process efficiency, cost-effectiveness and time saving with the potential to operate the business in real-time to curb the pain points of reconciliation at the middle and back-end levels by investment banks. The mentioned technology has its applications in investment banking in the form of interbank transactions, smart contract enforcement, remittance, regulatory reporting, cryptobanking, record sharing with storage, trade finance, data security, clearing with the settlement, increasing transparency, loan syndication, serving unbanked, know your customer (KYC) and anti-money laundering (AML). Reconciliation is one of the major activities of these banks at the back end, with tremendous human resources spread across many countries. There are numerous challenges concerned with inter-entity reconciliation, which arise due to many reasons like lack of quality information, reporting

(C) Vedapradha R and Hariharan Ravi. Published in Innovation \& Management Review. Published by Emerald Publishing Limited. This article is published under the Creative Commons Attribution (CC BY 4.0) licence. Anyone may reproduce, distribute, translate and create derivative works of this article (for both commercial and non-commercial purposes), subject to full attribution to the original publication and authors. The full terms of this licence maybe seen at http://creativecommons.org/licences/by/4.0/ legalcode.

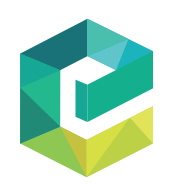


INMR

20,1

deadlines, tight schedules and decentralized communication between counterparties and players in the market. These reasons lead to differences in accounting information between the custodian and the investment bank, which end up publishing their financial results with these discrepancies being carried forward or left unaddressed for a long time; this is why they fail to connect in real-time (Devi, 2018).

It revolutionizes the stock markets by reducing intermediaries, offering regulatory built-in chips, simplifying post-trade settlements, establishing the market for security tokens and automated regulatory machines, facilitating dividend payments, fund-raising, asset management, token-based micro-investing, e-voting for bond and stockholders, tracking securities lending and blockchain-based mutual funds (Shah \& Jani, 2018). The information technology (IT) team must render constant support to the management both through infrastructural development and software application, in addition to training end-users, periodical up-gradation, resolution to technical issues, and testing, maintaining and reporting system performance (Racine \& Dancs, 2020). The bank must have sufficient financial support to test the prototype before actual implementation and to support the additional cost involved in training, accumulation, implementation and maintenance. The technical support team must assist issues related to resolutions, operations and business continuity processes (Hassani, Huang, \& Silva, 2018). Smart contracts are very promising in terms of removing long-lasting barriers to improve efficiency by eliminating transaction costs, improving processing time and rendering effective financial services to customers (O'Shields, 2017).

Therefore, we have identified a gap based on the previous studies conducted by various authors, i.e. to explore an innovative operational business model integrated with blockchain technology to enhance operational efficiency, especially in reconciliation across investment banks. Based on theoretical arguments and empirical evidence, our research questions are "Is there any relationship between innovative technology and return on investment (ROI), Can these banks develop a suitable operational model integrated with technology?"

Banks are currently encountering numerous challenges at the middle and back-end operations, causing them to be inefficient with expensive reconciliation processes and systems, tedious trade confirmation process, concern with data quality in failed trades, complex regulatory, compliance, client reporting, etc., in their daily routine at various levels of banking management. It is challenging for these banks in the industry to transform the data sharing process aiming at cost optimization. Hence, the study is focused on the adaptation of blockchain technology in these banks in enhancing the accounting professionals by reducing the maintenance cost of reconciliation ledgers and improving the performance with a unique model integrated with technology.

Thus, blockchain technology (Cryptobanking) facilitates the transformation of the reconciliation process of these banks with improved operational efficiency. Blockchain and settlement platforms offer inter-organization solutions facilitating the reconciliation of various transactions in real-time through a trust-based network by means of digital settlements with better consortium. Cryptobanking refers to the banking solutions offered by financial institutions with blockchain technology.

The practical implications of the study offer a promising application of the mentioned technology when adapted in operations focused on reducing cost, increasing efficiency and corporate governance, reducing mismatches and providing real-time transactional dashboards and on-boarding of participant entities through a customized application with instant reconciliation through ready-made interfaces for core systems with quick settlements on clouds. The overall operational cost of reconciliation is eliminated by using customized blockchain adaptors.

The study focuses on estimating the contribution of technology in improving the ROI and indicates the difference between technologies and the expected operating model. 


\section{Theoretical background}

Investment banking companies are often dealing with confidential clientele, market data involving huge costs, time and resources to be taken care of. These banks interact with many transactions daily related to seeding, lending, trades, corporate actions and many others, which become even more complex with exorbitant revenue expenses (costs) of facilities, services, managerial fees, tax allocations and dividends. They operate at different geographical levels with different time zones; accounting standards are transacted with multiple currencies, diverse regulatory norms, tax regimes requiring explicitly trained analysts to account for these price fluctuations and discrepancies in the accounting books, which must be reported to their head offices through inter-entity reconciliation.

There are various reasons to experience discrepancies in the books of accounting between an investment bank and the custodian which requires further reconciliation by operational analysts to investigate and take necessary actions to ensure clearance of the same. Some of the common reasons for discrepancies in cash are non-receipt of coupons or dividends, withholding of tax, incorrect coupon or dividends reflected at either of the parties due to incorrect rates, the entitlement of shares issues, pay date, failed trades, pay downs of principles in the form of redemption, income repatriation and delay at clearing houses. Stock discrepancies often are the results of unsettled or failed trades, income sweeps, inflated positions, multi-listed securities, securities mapped incorrectly, fractional shares held, future contracts reflected, corporate actions, rounding of shares and time zone differences (Vedapradha, Hariharan, \& Rajasekar, 2016).

The method of interactive reconciliation model for efficient block distribution known as Graphene to evaluate the performance was applied using analytics for better performance (Ozisik, Andresen, Bissias, Houmansadr, \& Levine, 2017). The model was improved through a combination of the bloom filter and invertible bloom lookup table, resulting in a much faster system with better performance through analysis, simulation and tested outcomes of cryptocurrencies (Ozisik et al., 2019). The blockchain application is considered as a panacea in addressing documentation, transfer of ownership, trading, payments, reconciliation, etc. Blockchain can improve the business models with optimization, enhancing efficiency and being much more secure (Zhu \& Wang, 2019). The increasing competition in the banking industry is forcing technological changes through innovations, making it inevitable to transform their business with revolutionary technology implemented in the areas of clearances, payments, credit information systems and customer database with better efficiency (Guo \& Liang, 2016). The proposed conceptual framework to the application of blockchain in the accounting profession is based on a single ledger where transactions are recorded on a distributed ledger which is validated by the parties before sending it to the counter party's system to eliminate redundancy in current accounting systems (Gomaa, Gomaa, \& Stampone, 2019).

Emerging innovative technologies can be applied in meeting the standards of service-level agreement in the business, which ensures data accuracy, security and better quality of standards. A comparative study has been developed on the offering of a solution to security concerns through a trusted third party (Singh \& Lee, 2017). The implementation of the technology applied to various complex systems enables the firms to evaluate the performance outcome attempting to venture into the novelty on the hyper ledger fabric services (Kocsis et al., 2018). Experiments were conducted to confirm the secured and shared transactions that can also facilitate useful trades by various players in the market based on the Paillier cryptosystem to assure the confidentiality of data sharing (Zhang, White, Schmidt, Lenz, \& Rosenbloom, 2018). Data can be stored and secured through networked cloud-based systems to ensure the validation of transactions. Computer networks operate with innovative infrastructures for companies, i.e. individuals to handle and manage their data (Ahmad, Kumar, Shrivastava, \& Bouhlel, 2018).

\section{EOM \\ approach to reconciliation in banking}


INMR

20,1

The invention relates to the application of technology in trading systems with cryptographic wallets by the users on a peer-to-peer network of computer nodes to ensure more secure transactions between the parties (Haldenby et al., 2021). The technique offers scalable reconciliation through a comparison between offline and online wallets in a blockchain network, where transactions traded on the platform are triggered through the network to generate smart contracts (Holland, Kiseleva, Grigoryan, \& Ra Dmcc, 2020). The future of banking, when adapted to this technology, was tested, resulting in economic efficiency, operating efficiency and efficient service to optimize the achievement of global financial infrastructure and sustainable development (Cocco, Pinna, \& Marchesi, 2017). The emphasis on the significance of disruptive innovative technology in business with the exponential development of its application indicates an adaptation of innovation technologies, leading to optimal results in the banking industry (Maslova, 2018). The implication of blockchain in the banking industry is global competitiveness through smart contracts, money remittance, digital assets transfer and automated banking operations (Peters \& Panayi, 2016). The application of blockchain beyond bitcoin concepts in the financial technology (Fin-Tech) sector helps to identify gaps and challenges (Eyal, 2017).

\section{Development of a conceptual theory}

The goal of this type of reconciliation is to ensure that the financial records are on the same page between the entities. A typical process of this reconciliation comprises transactions validated and verified, creating discrepancies in currencies, corporate actions, stock or cash balances, open trades, future settling coupons or dividends daily, which must be fixed before the closure of the books of accounts. The discrepancies unexplained always account for high risk from the managerial aspects in the form of losing goodwill, customer loss, money laundering, insider trading, etc. The reconciliation complexity involves limited counter-party visibility, unstandardized accounting methods, technological glitches, the risk of large transactions with high value and deviation from service agreements (Brandon, 2016). Banks require a robust mechanism to address the challenges of inter-entity reconciliation which enables channelizing the expertise of human resources into core business activities by creating value. The distributed ledger concept of seeking approval of a particular transaction simultaneously by all the parties involved is reconciled in real-time based on API integration with existing accounting systems. It also provides additional security with encrypted digital signatures that are auditable and secured. This mechanism eliminates discrepancies among the entries between inter-entities and infra-companies at a real-time front.

Hence, the first hypothesis framed is $\mathrm{H}_{0}{ }^{1}$ : Business process (a. customer strategy, b. employee development, c. change management, d. financial analysis, and capital management) and the introduction of technology influence the ROI.

The API software allows the banks to record transactions at each unit level irrespective of entries of infra-companies or inter-entities, approves the entries posted, and the same information is passed onto group level APIs. The unapproved transactions, when posted in the nodal chain of accounting and financial systems, are further queried within the parties and discrepancies are solved at the earliest without manual intervention (Treleaven, Brown, \& Yang, 2017). The banking company must develop robust governance and a clear framework to be operated by the employees when the technology is adopted. The roles and responsibilities of the staff must be clearly defined and assigned effectively, involving the identification of personnel who will ensure the establishment, run and support the system (Schuetz \& Venkatesh, 2020). There must be legal approval from the board of directors with a strategic blueprint of the technological flow to prevent data compliance, report streaming and ensure transparency and accuracy (Arjun \& Suprabha, 2020). The authors have conducted the study on the application of the mentioned technology in online payments and sales transaction systems focused on the various financial sectors where the outcome reflects that 
the new avenue is still being explored by these banks in terms of its feasibility towards the application due to the legal framework still awaiting a structured mechanism on its international payment transactions (Peter \& Moser, 2017).

The bridging model was applied to test the role of the technology in terms of trust and enforcement in the domain of currency with payment systems involved in banking transactions, inter-relating banking with technology (Christopher, 2016). Most of the investment banks often use different accounting methods and practices to suit the local regulations across the global captive business units which require reconciliation of interentity or between investment banks and custodian accounting data. These procedures are complex and time-consuming as both the stock and cash balance in different currencies must be daily accounted to help portfolio managers to make timely effective decisions.

Therefore, the second hypothesis designed $\mathrm{H}_{0}^{2}$ : Expected operating model (a. business process b. accounting, c. data reporting, d. operations, and e. pain points) differentiates in terms of technology implementation.

This technology helps banks streamline their actual data with contractual accounting data giving better visibility and control over global cash positions (Rella, 2019). The technology is applied to store data, remittances on currency exchanges and trading platforms. The current trading mechanism requires a trade date plus three days for the settlement of securities and payments which can cause a delay in settlements if either party fails to settle the trade leading to discrepancies in reconciliation. The application of this technology can lower operational costs, global trade, decentralize the clearing process, increase trust and reduce risk; in addition, client reporting is regulated (Akram, 2017). The exhaustive review of literature conducted by the authors reveals the various opportunities available in the banking and finance sector with the application of the technology in rendering their customers with excellent service. It also emphasizes the quality decisions made by the managers, adding value to their business (Osmani, El-Haddadeh, Hindi, Janssen, \& Weerakkody, 2020).

\subsection{Expected operational model}

The current study is based on the extension of the work done by the previous researchers who have already measured various business models integrated with technology in evaluating operations, competition, value creation, etc. The expected operating model proposed comprises five components, namely business process, paint points, operations, data reporting and accounting, which must be considered by these banks during the technological implementation. The business process gets narrowed down to the extent of activities performed at various levels of business by considering the reconciliation of cash along with stock expected between the parties either daily, monthly based or before the closure of books of accounts. It also involves settlements of various transactions related to trades with future settlement dates, dividends or coupons payable at a future date, i.e. cash settlements when entered through derivatives. There are different types of pain points encountered by human resources in the areas of trading, settlements, reporting, dispute management, compliance and reconciliation. The key area of implementation must be identified, tested and implemented at each phase or must be considered for integrated solutions. The operational level of implementation must be decided in advance by these banks either by the middle or back office. The decision-making with regards to the implementation of data and financial reporting to clients and stakeholders must be candid to prevent any pitfalls.

\section{Methodology}

The research study is empirical and restricted to the geographical area of urban districts of Bangalore considering the various active investment banks and their different levels of operations. A structured questionnaire was administered to collect the primary data from the 
INMR

20,1

respondents, i.e. employees of the leading foreign-based investment banks operating in urban localities. The researcher categorized the first section of a questionnaire comprising the respondents' demographic profile. The second part of the questionnaire comprises constructive statements based on a 5-point Likert scale related to technology and operations.

The stratified sampling method got applied to this study in reaching out to 120 respondents working at different designations in the investment banks operating in the geographical locality of urban Bangalore. Thirty-five investment banks were identified, with approximately 40,000 employees, $10 \%$ of this population would result in a sample size of 400 individuals. However, only 150 responses were received out of which 30 were incomplete. Therefore, the researcher could access only 120 concrete responses due to the COVID-19 pandemic, which was sufficient to conduct the study.

The data type considered for the study is primarily through a structured questionnaire based on the 5-point Likert Scale divided into three parts. The first part of the questionnaire includes a demographic profile of the respondents; the second part includes technological implementation, pain points of employees and operational segment questions; the third part of the questionnaire consists of statements related to the business process, technology and data reporting.

The demographic and awareness variables are nominal. The variables of business process, technology and data reporting are ordinal. The compilation of the chosen variables was obtained based on previous research, which was considered suitable for the current study. The demographic variables observed are age, gender, qualification and annual income. The business process variables consist of customer strategy, employee development, change management, financial analysis, capital management and technology, which constitute the predictors of ROI. The expected operating model consists of other variables, namely business process, accounting, data reporting, operations and pain points.

The statistical software used for the study is SPSS (Statistical Package for Social Sciences), which was utilized to verify the hypothesis by applying a few statistical tests, namely regression and analysis of variance (ANOVA).

\section{Results}

\subsection{Reliability and validity tests}

Reliability analysis was performed on the variables comprising of 23 items. The Cronbach's alpha indicates acceptable reliability ( $\alpha=0.915, N=120$ ). All the items appeared to be worthy of retention, confirming the high reliability of the items.

Kaiser-Meyer-Olkin measure of sampling adequacy and Bartlett's test $(\mathrm{KMO}=0.922$, $\left.\chi^{2}(231)=1564.901, p<0.001\right)$ indicate that the sample adequacy confirms the validity (Kaiser \& Rice, 1974).

\subsection{Percentage analysis}

Simple percentage analysis was conducted to examine the demographic profile of the respondents. Gender reflects that $54.2 \%$ of the employees are male with $44.2 \%$ as females. $84.2 \%$ of the respondents fall within the age group " $18-25 \mathrm{yrs}$ ", $11.7 \%$ are within " $26-35 \mathrm{yrs",}$ $1.7 \%$ within " $26-45$ yrs" and only $2.5 \%$ respondents are aged above 46 yrs. $75.8 \%$ of the employees are undergraduate, whereas $20 \%$ are postgraduates working across various levels of operational segments. $51.7 \%$ of the employees earn an annual income of less than Rs. $100,000,23.3 \%$ earn between "Rs. 200,000-500,000 lakhs", 15\% between "600,000-900,000" and $10 \%$ earn above Rs. 900,000 lakhs.

\subsection{Stepwise multiple regression analysis}

The above-mentioned type of regression was applied to show if the variables of interest (blockchain technology) can explain a statistically significant amount of variance in the 
dependent variable ROI after accounting for all other variables. The results obtained from the analysis are presented in Table 1.

To approach the research question, a hierarchical regression analysis was conducted to evaluate the prediction of the dependent variable ROI from the independent variables, namely Customer strategy (CS), Employee development (ED), Change Management (CM), Financial Analysis (FA) and Capital Management (CA). For the first block of analysis, the predictor variables $\mathrm{CS}, \mathrm{ED}, \mathrm{CM}, \mathrm{FA}$ and $\mathrm{CA}$ were analyzed. The results of the block hierarchical linear regression analysis revealed a positive model, statistically significant $(\phi<0.01)$. Additionally, the $R^{2}$ value (0.944) associated with this regression model suggests that the five independent variables account for $94.4 \%$ of the variation in $\mathrm{ROI}$, which means that $5.6 \%$ of the variation in ROI could not be explained by these five predictors alone. However, a different outcome was found in the analysis of the second block. In the second block, the predictor variable technology (TE) was added to the analysis. The results of this hierarchical linear regression analysis revealed a better, statistically significant model $(p<0.01)$. Additionally, the $R^{2}$ value $(0.985)$ associated with this regression model suggests that the six independent variables account for $98.5 \%$ of the variation in ROI, which means that just $1.5 \%$ of the variation in ROI couldn't be explained by these six predictors. Hence, the derived regression equation is $Y$ $(\mathrm{ROI})=0.839+1.294(\mathrm{CS})+1.110(\mathrm{ED})+1.699(\mathrm{CM})+1.701(\mathrm{FA})+1.669(\mathrm{CA})+1.449(\mathrm{TE})$.

The analysis indicates that regarding controlling for $\mathrm{CS}$, the regression coefficient $(B=0.110, p<0.01)$ associated suggests that with each additional unit of CS, the ROI increases approximately by 1.294 units. Regarding the controlling for economic development, the regression coefficient $(B=0.095, p<0.01)$ associated suggests that with each additional unit of $\mathrm{ED}$, the ROI increases approximately by 1.110 units. In the case of $\mathrm{CM}$, the regression coefficient $(B=0.124, p<0.01)$ associated suggests that with each additional unit of $\mathrm{CM}$, the ROI increases approximately by 1.699 units. In the case of Financial Analysis, the regression coefficient $(B=0.150, p<0.01)$ associated suggests that with each additional unit of $\mathrm{FA}$, the ROI increases approximately by 1.701 units. In the case of $C A$, the regression coefficient $(B=0.152, p<0.01)$ associated suggests that with each additional unit of $\mathrm{CA}$, the ROI increases approximately by 1.669 units. In the case of technology, the regression coefficient $(B=0.503, p<0.01)$ associated suggests that with each additional unit of CA, the ROI increases approximately by 1.449 units. Therefore, the null hypothesis was rejected and the alternative accepted.

\subsection{Analysis of variance}

The one-way ANOVA was used to determine any statistically significant differences between the means of the considered independent groups. Table 2 projects the difference between the EOM and their implementation of technology compared with their means.

\begin{tabular}{|c|c|c|c|c|c|c|}
\hline Variables & $B$ & $\begin{array}{l}\text { Block } 1 \\
\text { SE } B\end{array}$ & $\beta$ & $B$ & $\begin{array}{l}\text { Block } 2 \\
\text { SE } B\end{array}$ & $\beta$ \\
\hline $\mathrm{CS}$ & 3.118 & 0.400 & $0.265^{* *}$ & 1.294 & 0.231 & 0.110 *** \\
\hline ED & 1.676 & 0.374 & $0.143^{* * *}$ & 1.110 & 0.196 & $0.095^{* * *}$ \\
\hline $\mathrm{CM}$ & 2.522 & 0.419 & $0.184^{* *}$ & 1.699 & 0.221 & $0.124^{* *}$ \\
\hline FA & 3.068 & 0.365 & $0.270^{* * *}$ & 1.701 & 0.204 & $0.150^{* * *}$ \\
\hline $\mathrm{CA}$ & 3.541 & 0.336 & $0.323^{* * *}$ & 1.669 & 0.203 & $0.152^{* *}$ \\
\hline TE & - & - & - & 1.449 & 0.082 & $0.503^{* *}$ \\
\hline$R$ & & 0.972 & & & 0.993 & \\
\hline$R^{2}$ & & 0.944 & & & 0.985 & \\
\hline$F$ statistic & & 379.62 & & & 309.84 & \\
\hline Sig. & & $(0.000)^{* * *}$ & & & $(0.000)^{* * *}$ & \\
\hline
\end{tabular}

Source(s): Computed from primary data.**Sig @ 1\% level

Table 1.

Variables and coefficients in predicting the ROI 


\begin{tabular}{|c|c|c|c|c|c|}
\hline \multirow{3}{*}{$\begin{array}{l}\text { INMR } \\
20,1\end{array}$} & \multirow[b]{2}{*}{ Expected operating model } & & & & \\
\hline & & Implementation & Mean square & $F$ value & Sig. \\
\hline & Operations & Between groups & 0.373 & 1.704 & 0.036 \\
\hline \multirow{5}{*}{24} & & Within groups & 0.219 & & \\
\hline & Pain points & Between groups & 2.465 & 1.071 & 0.391 \\
\hline & & Within groups & 2.301 & & \\
\hline & Business process & Between groups & 122.265 & 72.413 & $(0.000)^{* * *}$ \\
\hline & Accounting & Between groups & $\begin{array}{r}1.688 \\
124.570\end{array}$ & 78.048 & $(0.000)^{* * *}$ \\
\hline \multirow{4}{*}{$\begin{array}{l}\text { Table } 2 \text {. } \\
\text { Difference between } \\
\text { means of EOM and } \\
\text { technology }\end{array}$} & & Within groups & 1.596 & & \\
\hline & Data reporting & Between groups & 120.451 & 77.051 & $(0.000)^{* * *}$ \\
\hline & & Within groups & 1.563 & & \\
\hline & \multicolumn{5}{|c|}{ Source(s): Computed from primary data. **Sig @ 1\% level } \\
\hline
\end{tabular}

There is a statistically significant difference between the expected model and implementation of the blockchain technology as the $p$-value is 0.000 , significant at $1 \%$ for Business Process $(F=72.413)$, Technology $(F=78.048)$ and Data Reporting $(F=77.051)$. The probability value is significant at the $5 \%$ level for Operations $(F=1.704)$. There is no statistical significance in pain points $(F=1.071, p>0.05)$. Hence, the null hypothesis was rejected, and the alternative hypothesis accepted.

\section{Findings}

There is a strong and statistically high association between technology and business process $(F=72.413)$, accounting $(F=78.048)$, and data reporting $(F=77.05)$ at a $1 \%$ level. A moderate association was observed between technology and operations $(F=1.704)$, significant at $5 \%$. These banks, which are spread across the globe with their operations mandated to apply distinct accounting methods to suit the local country's requirements and regulations, find it extremely challenging to perform inter-entity reconciliation and consolidation of reports. Hence, the technology renders optimum solutions making the process of reconciliation and financial reporting more accurate and in real-time. However, the pain points of the employees working at various levels of operations did not have any significance with the technological implementation. It is because of no statistical evidence for the same as the workflow is treated at the business level and not at the employee level in fixing the challenges. It confirms that there is a significant variance between the EOM and technological implementation.

There is a significant difference in reconciliation performed by operational analysts when the blockchain technology is adopted, considering its importance among investment banks.

The variables CA $(B=3.541, \beta=0.323), \mathrm{CS}(B=3.118, \beta=0.265)$ and $\mathrm{FA}(B=3.068$, $\beta=0.270)$ are the most influencing factors from the first block with higher predicting ability of ROI. Considering the results of the second block, $\mathrm{FA}(B=1.701, \beta=0.150), \mathrm{CA}(B=1.699$, $\beta=0.152), \mathrm{CM}(B=1.699, \beta=0.124)$ are the variables with maximum prediction ability, and blockchain technology is the most influencing factor in the model for enhancing the ROI because the business can be successful only when there is a strategic balance between the customers and cost factors.

The findings of the study reveal that the introduction of blockchain technology (Cryptobanking) has a statistically significant relationship among innovative technologies on ROI. The innovative reconciliation approach with the integrated application of EOM improves the overall banking operational performance. The advanced technology in banking has brought their business into a much more sophisticated level. 


\section{Scope and limitations}

The research was confined to the mere banking industry of a particular type. A similar technique or study is useful and applicable to other industries where the comparison between pre- and post-implementation of blockchain could be assessed. The researcher could not increase the sample size due to the pandemic outbreak of COVID-19, considering diminished personal interactions and social distancing and the difficulty to reaching out to respondents.

\section{Conclusion}

Blockchain technology eliminates the validation and investigation of accounting information from the various databases while performing the reconciliation of transactions saving time, cost and rendering the reports in real-time. It also provides a solution to the auditors when the information is spread across different blockchains with predictable operational cost, market analysis, reduced operational risks, time to resolve the discrepancies and real-time liquidity information. There is a provision for sharing the data with all the counterparties approving the transaction, simultaneously reducing the discrepancies. The settlements between counterparties and banks can be netted off automatically, reducing fees with automatic multilateral settlements, which encourages the management to focus on core business. Hence, the study has resulted in a positive approach towards the implementation of this technology in reconciliation among investment banks. However, it is no excuse for challenges like limited visibility, system-level variation, level of accuracy, volume of transactions and data accumulated, which must be considered by these banks before implementation.

Therefore, based on the findings presented in this study, we conclude that there is a strong relationship between innovative technology and ROI. The banks analyzed herein design a sustainable operational model integrated with blockchain technology that can integrate the business with significant changes in reconciliation.

The study has emphasized the applicability of the mentioned technology to a greater level as blockchain-enabled reconciliation can create wonders by reducing costs and improving scalability with better performance. It can help operational analysts in projecting real-time discrepancies in both cash and stock reconciliation improving timely communication between the analyst and portfolio managers, facilitating timely decisions. It also increases the authenticity with greater consistency in the accounting systems adopted for the reconciliation between the investment banker and the custodian. It improves the business process with quality risk management techniques and transparent data reporting to clients. Hence, the business process has a significant impact on ROI when integrated with the mentioned technology based on EOM.

There is a scope to investigate the application of this technology at the front-office level that reduces the turnaround time of bringing the clients on board and the fund initiation process.

\section{References}

Ahmad, F. A., Kumar, P., Shrivastava, G., \& Bouhlel, M. S. (2018). Bitcoin: Digital decentralized cryptocurrency. Handbook of research on network forensics and analysis techniques (pp. 395415). IGI Global.

Akram, W. (2017). Blockchain technology: Challenges and prospects. International Journal of Advanced Research in Computer Science, 8(9), 642-644.

Arjun, R., \& Suprabha, K. R. (2020). Innovation and challenges of blockchain in banking: A scientometric view. International Journal of Interactive Multimedia and Artificial Intelligence, 6(3).

Brandon, D. (2016). The blockchain: The future of business information systems. International Journal of the Academic Business World, 10(2), 33-40.

EOM
approach to

reconciliation

in banking 
INMR

20,1

Christopher, C. M. (2016). The bridging model: Exploring the roles of trust and enforcement in banking, bitcoin, and the blockchain. Nevada L.J., 17, 139.

Cocco, L., Pinna, A., \& Marchesi, M. (2017). Banking on blockchain: Costs savings thanks to blockchain technology. Future Internet, 9(3), 25.

Devi, S. (2018). Banking Inter entity reconciliation made simple with blockchain. Retrieved 15 April 2020, from available at: https://www.oodlestechnologies.com/blogs/Banking-Inter-entityReconciliation-Made-Simple-with-Blockchain/.

Eyal, I., 2017. Blockchain technology: Transforming libertarian cryptocurrency dreams to finance and banking realities. Computer, 50(9), 38-49.

Gomaa, A. A., Gomaa, M. I., \& Stampone, A. (2019). A transaction on the blockchain: An AIS perspective, intro case to explain transactions on the ERP and the role of the internal and external auditor. Journal of Emerging Technologies in Accounting, 16(1), 47-64.

Guo, Y., \& Liang, C. (2016). Blockchain application and outlook in the banking industry. Financial Innovation, 2(1), 24.

Haldenby, P. A. J., Mahadevan, R., Lee, J. J. S., Chan, P. M. W. \& Del Vecchio, O. (2021). U.S. Patent No. 11,126,975. Washington, DC: U.S. Patent and Trademark Office.

Hassani, H., Huang, X., \& Silva, E. (2018). Banking with blockchained big data. Journal of Management Analytics, 5(4), 256-275.

Holland, D., Kiseleva, K., Grigoryan, V., \& Ra Dmcc, R., 2020. Scalable reconciliation of crypto assets in a blockchain network. U.S. Patent Application 16/038,680.

Kaiser, H. F., \& Rice, J. (1974). Little jiffy, mark IV. Educational and Psychological Measurement, 34(1), 111-117.

Kocsis, I., Klenik, A., Pataricza, A., Telek, M., Deé, F., \& Cseh, D. (2018). Systematic performance evaluation using the component-in-the-loop approach. International Journal of Cloud Computing, 7(3-4), 336-357.

Maslova, N. (2018). Blockchain: Disruption and opportunity. Strategic Finance, 100(1), 24-30.

O'Shields, R. (2017). Smart contracts: Legal agreements for the blockchain. North Carolina Banking Institute, 21, 177.

Osmani, M., El-Haddadeh, R., Hindi, N., Janssen, M., \& Weerakkody, V. (2020). Blockchain for next generation services in banking and finance: cost, benefit, risk and opportunity analysis. Journal of Enterprise Information Management, 34(3), 884-899.

Ozisik, A. P., Andresen, G., Bissias, G., Houmansadr, A., \& Levine, B. (2017). Graphene: A new protocol for block propagation using set reconciliation. Data privacy management, cryptocurrencies and blockchain technology (pp. 420-428). Cham: Springer.

Ozisik, A. P., Andresen, G., Levine, B. N., Tapp, D., Bissias, G., \& Katkuri, S. (2019). Graphene: Efficient interactive set reconciliation applied to blockchain propagation. Proceedings of the ACM Special Interest Group on Data Communication (pp. 303-317).

Peter, H., \& Moser, A. (2017). Blockchain applications in banking and payment transactions: Results of a survey. European Financial Systems, 141, 141.

Peters, G. W., \& Panayi, E., 2016. Understanding modern banking ledgers through blockchain technologies: Future of transaction processing and smart contracts on the internet of money. In Banking beyond banks and money (pp. 239-278). Cham: Springer.

Racine, V., \& Dancs, A. (2020). A closer look at the promise of the blockchain in banking and biobanking. In How social forces impact the economy (pp. 97-117). Routledge.

Rella, L. (2019). Blockchain technologies and remittances: From financial inclusion to correspondent banking. Frontiers in Blockchain, 2, 14.

Schuetz, S., \& Venkatesh, V. (2020). Blockchain, adoption, and financial inclusion in India: Research opportunities. International Journal of Information Management, 52, 101936. 
Shah, T., \& Jani, S. (2018). Applications of blockchain technology in banking and finance. Vadodara: Parul University.

Singh, I., \& Lee, S. W. (2017, November). Comparative requirements analysis for the feasibility of blockchain for secure cloud. In Asia Pacific Requirements Engineering Conference (pp. 57-72). Singapore: Springer.

EOM approach to reconciliation in banking

Treleaven, P., Brown, R. G., \& Yang, D. (2017). Blockchain technology in finance. Computer, 50(9), $14-17$.

Vedapradha, R., Hariharan, R., \& Rajasekar, A. (2016). Investment banking: Reconciliation of fixed income securities. Mauritius: Lambert Academic Publishing.

Zhang, P., White, J., Schmidt, D. C., Lenz, G., \& Rosenbloom, S.T. (2018). FHIRChain: applying blockchain to securely and scalably share clinical data. Computational and Structural Biotechnology Journal, 16, 267-278.

Zhu, X., \& Wang, D. (2019). Application of blockchain in document certification, asset trading, and payment reconciliation. Journal of Physics: Conference Series, IOP Publishing, 1187(5), 052080.

\section{Corresponding author}

Vedapradha R can be contacted at: vedahariharan@gmail.com

For instructions on how to order reprints of this article, please visit our website:

www.emeraldgrouppublishing.com/licensing/reprints.htm

Or contact us for further details: permissions@emeraldinsight.com 